\title{
Effects of interaural level differences on the externalization of sound
}

\author{
Catic, Jasmina; Santurette, Sébastien; Dau, Torsten; Buchholz, Jorg
}

Published in:

Acoustical Society of America. Journal

Publication date:

2012

Document Version

Peer reviewed version

Link back to DTU Orbit

Citation (APA):

Catic, J., Santurette, S., Dau, T., \& Buchholz, J. (2012). Effects of interaural level differences on the externalization of sound. Acoustical Society of America. Journal, 3520.

\section{General rights}

Copyright and moral rights for the publications made accessible in the public portal are retained by the authors and/or other copyright owners and it is a condition of accessing publications that users recognise and abide by the legal requirements associated with these rights.

- Users may download and print one copy of any publication from the public portal for the purpose of private study or research.

- You may not further distribute the material or use it for any profit-making activity or commercial gain

- You may freely distribute the URL identifying the publication in the public portal

If you believe that this document breaches copyright please contact us providing details, and we will remove access to the work immediately and investigate your claim. 


\title{
Session 5pAAb
}

\section{Architectural Acoustics and Psychological and Physiological Acoustics: Psychoacoustics in Rooms III (Lecture/Poster Session)}

\author{
Philip Robinson, Cochair \\ robinp@rpi.edu \\ Bernhard Seeber, Cochair \\ bernhard.seeber@ihr.mrc.ac.uk
}

\section{Invited Papers}

5pAAb1. Effects of interaural level differences on the externalization of sound. Jasmina Catic, Sebastien Santurette, Torsten Dau (Centre for Applied Hearing Research, Technical University of Denmark, Lyngby, Denmark, jac@elektro.dtu.dk), and Jörg Buchholz (National Acoustic Laboratories, Chatswood, Australia)

Distant sound sources in our environment are perceived as externalized and are thus properly localized in both direction and distance. This is due to the acoustic filtering by the head, torso, and external ears, which provides frequency-dependent shaping of binaural cues such as interaural level differences (ILDs) and interaural time differences (ITDs). In rooms, the sound reaching the two ears is further modified by reverberant energy, which leads to increased fluctuations in short-term ILDs and ITDs. In the present study, the effect of ILD fluctuations on the externalization of sound was investigated. A psychoacoustic experiment was performed in a standard IEC 268-13 listening room by normal-hearing listeners. Individual binaural room impulse responses were used to simulate a distant speech source delivered via headphones. The speech signal was then processed such that the naturally occurring fluctuations in the ILDs were compressed, while the ITDs were preserved. This manipulation reduced the perceived degree of externalization mainly for broadband and highpass filtered speech. In the case of lowpass filtered speech, the compression of ILD fluctuations did not affect externalization. Overall, for sounds that contain frequencies above about $1 \mathrm{kHz}$ the ILD fluctuations were found to be an essential cue for externalization.

\section{3:00}

5pAAb2. Auditory localization in realistic environments by normal-hearing and hearing-impaired listeners. Jorg M. Buchholz, Virginia Best, and Gitte Keidser (National Acoustic Laboratories, Australian Hearing, Chatswood NSW 2067, Australia, jorg.buchholz@ nal.gov.au)

The ability to correctly localize sounds is important for general awareness of the auditory scene and communication in adverse acoustic conditions. However, most localization studies are performed in rather simple and artificial conditions. In particular, very few studies have considered localization in reverberant environments or in the presence of complex interferers, and no studies have systematically investigated the effect of distance. In the present study, localization performance was therefore measured as a function of source-receiver distance using a virtual auditory environment. With increasing source-receiver distance the direct-to-reverberation energy ratio decreases and the auditory system increasingly relies on mechanisms related to the precedence effect. Both aspects may be particularly problematic for hearing-impaired listeners. The acoustics of a cafeteria was simulated with the room acoustic software ODEON for a large number of source-receiver locations. Signals were generated for a 3D array of 41 loudspeakers using the loudspeaker-based room auralization (LoRA) toolbox. Localization performance was measured in normal-hearing and hearing-impaired listeners with a bilateral hearing loss in the simulated cafeteria with and without a multi-talker speech background. The experimental results were correlated with a number of acoustic measures derived from dummy head recordings of the different acoustic conditions.

\section{$3: 20$}

5pAAb3. Explorations by the visually impaired of real and virtual rooms. Brian Katz (LIMSI-CNRS, BP 133, Université Paris Sud, 91403 Orsay, France, brian.katz@limsi.fr), and Lorenzo Picinali (Faculty of Technology, De Montfort University, The Gateway Leicester, LE1 9BH, UK)

Virtual acoustic simulations of two interior environments were presented to visually impaired individuals. Interpretations of the acoustic information, through block map reconstructions, were compared to reconstructions following in-situ exploration as well as playback of binaural and Ambisonic walkthrough recordings. Simulations used off-line HOA RIR synthesis and a hybrid rendering combining pre-convolved signals and real-time convolutions for sounds related to user displacement and self-generated noise. Results showed that listening to passive binaural playback or Ambisonic playback, which also included interactive head-movements, provided less usable information than a virtual simulation with respect to the acquisition of spatial information of an interior architectural environment. The presence of both dynamic cues relative to displacement and controlled events such as finger snaps, as included in the virtual condition, were deemed highly valuable by the participants. Virtual acoustic simulations provided acoustic information that allowed for highly 